\title{
Task Force Report 4. Report of the Task Force on Marketing and Communications
}

\author{
Jobn C. Dickinson, $M D^{1}$ \\ Kenneth L. Evans, MD' \\ Jan Carter $^{3}$ \\ Kevin Burke \\ ${ }^{1}$ Chair, Task Force 4, Rochester, NY \\ ${ }^{2}$ Vice Chair, Task Force 4, Stillwater, Okla \\ ${ }^{3}$ Staff Executive, Task Force 4, Leawood, Kan \\ ${ }^{4}$ Staff Executive, Task Force 5, Washington, DC
}

\begin{abstract}
BACKGROUND To ensure the success of the proposed New Model of family medicine and to create a better understanding of the nature and role of family medicine, an effective communications plan must be developed and implemented. This Future of Family Medicine task force report proposes strategies for communicating the role of family physicians within medicine, as well as to purchasers, consumers, and other entities.
\end{abstract}

METHODS After reviewing the findings from the research conducted for the Future of Family Medicine project, the task force presents a preliminary brandpositioning strategy for family medicine messages. Based on this strategy, the task force identifies 5 major audiences to which family medicine communications should be directed. A consistent method was used to determine optimum strategies to address each audience: defining the audience, assessing the literature and other pertinent evidence, identifying the communication objectives, determining the key messages, developing brand promises, and proposing strategies and tactics to support the messages and objectives. Preliminary communications plans are then presented for each of the 5 target audiences.

MAJOR FINDINGS It is important that the organizations involved in family medicine make a multiyear commitment of resources to implement and support an aggressive communications strategy, which is based on key messages to target audiences. A concerted effort is particularly needed to address the declining interest among medical students in the specialty. Implementing a comprehensive family medicine career development program may be one effective strategy to reverse this trend. To help eliminate the current confusion among the public regarding family medicine and to promote clarity and consistency in terminology, the specialty should replace the name family practice with family medicine and a new graphic symbol for the discipline of family medicine should be developed.

CONCLUSION As a discipline, family medicine has failed to formulate and deliver a compelling message. New communications strategies must be implemented that will reach audiences in terms they understand and care about and in ways that convey a sense of the exciting role family physicians will play in the future. By actively implementing the communications plans described in this report, the specialty can enhance the impact and help ensure the widespread implementation of the proposed New Model of family medicine.

Ann Fam Med 2004;2:S75-S87. DOI: 10.1370/afm.137.

TASK FORCE CHARGE: Determine strategies for communicating the role of family physicians within medicine and health care, as well as to purchasers and consumers.

\section{INTRODUCTION}

Excellence is not a gift from the gods. It is a buman trait that is acquired only by relentless training and rutbless self-assessment... We are what we repeatedly do. Excellence is not a glamorous or singular achievement. It's a babit.

John Gardner, Founder, Common Cause 
$\mathrm{T}$ ask Force 4 accepts and affirms the Future of Family Medicine (FFM) research findings. This extensive self-study yields an important conclusion regarding communication: as a discipline, family medicine has failed to formulate and deliver a compelling message.

In addition, this task force firmly supports the proposed New Model of family medicine. An essential strategy to ensure its future success will be a comprehensive plan of communication.

The extensive research performed for this study provides a foundation and reference point for developing communication strategies and messages targeted to the attitudes and expectations of various constituencies. Additional depth of field is necessary, however, to ensure that the messages are clearly understandable to key audiences. Translating some of the information generated by the FFM research into commonly understood language suitable for a diverse set of audiences is a primary goal of this report. The messages proposed in this document seek to address diverse audiences in terms they understand and care about and in compelling terms that portray how family physicians will deliver health care value into the future.

The changing role of family physicians and the communication of this role must be considered in the context of the following sweeping changes that are taking place in the health care environment ${ }^{1}$ :

- The patient-physician relationship is changing and will continue to evolve in the future.

- Americans are living longer, and the elderly comprise a larger and more dominant segment of the US population.

- New technologies offer a wide range of communications options that were not available a decade or two ago.

- Nongovernmental health organizations wield growing influence in the health care enterprise.

- Silo mentality still impedes communication and collaboration among hospitals, insurers, medical organizations, other health professional organizations, consumer groups, government, industry, and academia.

- Evidence-based medicine is emerging as perhaps the best opportunity to balance scientific care with humanistic care.

- Predictive medicine and preventive medicine are making inroads with health care providers and consumers alike.

\section{BRAND-POSITIONING STRATEGY}

To communicate the core messages of family medicine effectively, the messages must be crafted in the way the discipline wants various audiences to perceive, think, and feel about family medicine. In other words, a brand-positioning strategy must be designed for family medicine's messages. This strategy should consist of a brand identity and a brand position statement. The brand-positioning strategy will state the reason for the specialty's existence; evolve consistently with (or preferably help shape) long-term developments in the health care market; provide the most meaningful benefit(s) the specialty wants to and can own $n_{i}$ make the benefit(s) tangible and legitimate and, therefore, credible; and articulate a clear and compelling personality of family medicine, that is, create a brand identity.

Brand identity consists of 3 components: (1) physical, which encompasses the look, packaging, and function $_{i}(2)$ emotional, which is based on experiences, associations, images and feelings; and (3) rational, which answers the question, What's in it for me?

The brand identity for family medicine can be articulated in the following brand position statement:

The Family Physician: Your trusted personal physician. Keeping you well by bumanizing the science of medicine.

This statement is designed to capture 6 characteristics that emerged during the research process as the foundation of the specialty's identity. Figure 1 contains a graphic summary of these ideas.

Together, these brand constructs provide a blueprint for all FFM communications, particularly the portrayal and marketing of the new role of family medicine. An essential step in effective communication is to specify the target audiences. The task force identified 5 primary audiences to whom distinct messages regarding the future of family medicine should be directed: family physicians, other physicians and health care providers, medical students, government and other purchasers of health care, and the public and patients.

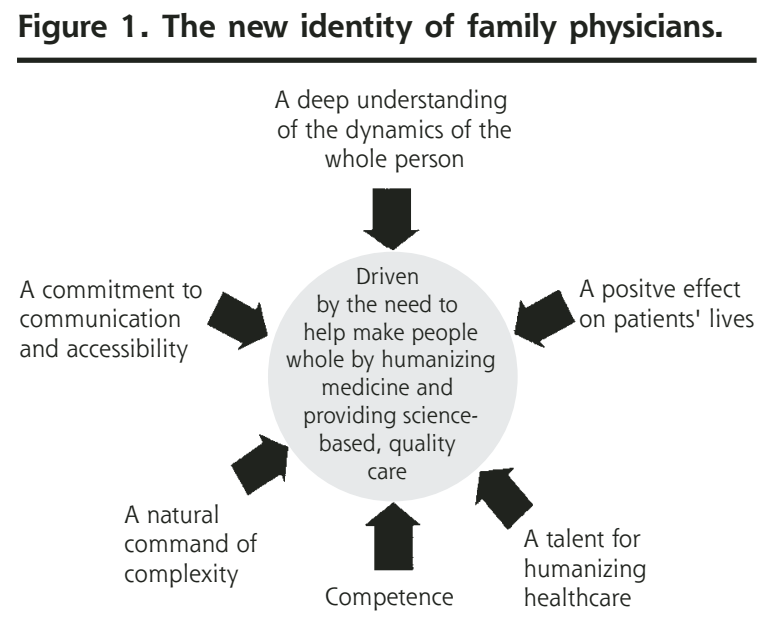

Source: Siegel \& Gale, New York. 
This task force then determined a consistent format to use as an outline for communications to these groups: define the audience, identify the objective(s) of the communications, determine the messages to convey those objectives, develop brand promises (ie, what the New Model promises to deliver if a family physician adopts it), and develop strategies and tactics to support the messages and objectives.

Following are individual communications plans for each of the 5 target audiences listed above. Each message set below is associated with specific proofs in the form of FFM research findings, the general literature, and expert counsel. Examples appear as relevant research in Appendix A to this report.

\section{COMMUNICATIONS PLAN FOR FAMILY PHYSICIANS}

\section{The Audience}

Family physicians are the most important audience for the message regarding the New Model of family medicine. Their understanding, involvement, and personification of these changes are central to transforming the discipline.

A strength of family medicine is its heterogeneity, expressed as variability in scope of services, practice location (urban, suburban, rural), practice arrangement (solo, group, etc), demographic characteristics of the patient population, and financial attributes of the practice. This heterogeneity also presents a communication challenge. The New Model must be recognizable by its consistent features, yet pliable enough to accommodate the various skills and interests of its constituents. One useful metaphor is the proposed design of fuel-cell powered automobiles. ${ }^{2} \mathrm{~A}$ basic chassis will contain the major mechanical components and the power plant. All of the passenger features (seats, storage, entertainment, etc) will be contained in a versatile cabin that is bolted to the chassis and can be upgraded according to customer preference. In the same manner, the New Model of family medicine must achieve both consistency and flexibility. The corresponding messages to family physicians must highlight these features, taking into account the widely varying circumstances in which family physicians practice medicine.

\section{Objectives}

- Move family physicians to a consensus that the current practice model has limitations and that it must be fixed.

- Emphasize the strengths of the New Model of family medicine and how it will ensure professional and personal satisfaction and success.
- Communicate to all family physicians the potential versatility of the New Model.

\section{Messages to Family Physicians}

- The current family medicine model needs to be modified for the 21 st century.

- The New Model will emphasize the patient-physician relationship.

- Family physicians who practice under the New Model will be rewarded appropriately for their services.

- The New Model will be applicable to all physicians in family medicine.

- The New Model will improve collegiality and the public perception of the specialty and will be more attractive to medical students.

\section{Brand Promises}

By implementing all the aspects of the New Model that are applicable to their practice, family physicians will be able to achieve and experience the following:

- High-quality interactions with their patients

- A satisfying career with financial and nonfinancial rewards

- A multidimensional career that allows family physicians to pursue individual goals

- Intellectual stimulation; a specialty in which physicians will not suffer boredom

- Technologically advanced health care

- An esteemed career with respect from colleagues and patients

- An opportunity to make a difference in the lives of patients, their families, and the community

\section{Strategies and Tactics}

Strategy 1. Develop a concise PowerPoint presentation that highlights the FFM research and recommendations as a means to secure buy-in for the New Model. Make the PowerPoint presentation available to all FFM project members, affiliated family medicine organizations, and family medicine leaders (past and present).

\section{Tactics}

- Present to family physicians at hospital staff meetings, regional meetings, state conferences, town hall gatherings, and the Annual Scientific Assembly of the American Academy of Family Physicians.

- Present to other physician groups.

- Present to family medicine residents.

- Present to medical students at the national conference, state conferences, medical schools, and family medicine interest groups network meetings.

- Present to constituencies of affiliated organizations.

- Place on-line at all applicable sites.

- Create feedback mechanisms for comment. 
Strategy 2. Develop a uniform brand image of the New Model recognizable by family physicians to be used at both the national and state levels.

\section{Tactics}

- Develop messages that convey a unified image of the New Model for all communications.

- Develop a logo to support this imagery.

- Integrate existing communication vehicles to strengthen the brand image.

Strategy 3. Use a variety of communication vehicles to reach the total family medicine population, explaining the New Model and how it will work and providing resources to enable family physicians to implement their own localized communication plans.

\section{Tactics}

- Develop a monograph that summarizes the FFM initiative and explains the New Model.

- Develop a series of articles to build support for the New Model.

- Communicate the new role of family medicine and implement communication strategies through all communications available to the supporting organization members (conferences, newsletters, Web site, etc).

- Conduct professional development, communication, and branding sessions at conferences, on the Internet, and through other means.

- Create a "how-to family medicine brand book" to use at all supporting organization headquarters. Develop a version for all organization membership and make available on CD-ROM, the Internet, and in hard copy.

- Create turnkey communications materials for use by family physicians with their patients and in their communities, to promote consistency of look and message while ensuring enough flexibility to meet the needs of individual practices (eg, to enable family physicians to incorporate human interest stories that would appeal to the local media).

Strategy 4. Educate family physicians about how the patient-physician relationship is expected to evolve.

\section{Tactics}

- Describe new methods of communication and interaction; specifically, technological innovations (eg, e-mail, personal digital assistants, Internet).

- Develop prototypes of communications as examples to make operational and improve efficiency.

- Describe new reimbursement strategies (eg, emergency medical service codes, asynchronous communications, skill training).
- Describe the various applications of the New Model for different practice settings and markets.

Strategy 5. Use market research to validate messaging and tactics of the communications program.

\section{Tactics}

- Implement qualitative and quantitative assessment projects.

- Secure baseline data to measure the success of these programs.

- Follow with recurring data inputs (surveys) to monitor, assess, and revise ongoing programs.

\section{COMMUNICATIONS PLAN FOR OTHER PHYSICIANS AND HEALTH CARE PROVIDERS}

\section{The Audience}

Other physicians and health care providers can and do have great influence on the public and professional perception of family physicians. The primary audience in this category is physicians who practice in specialty fields other than family medicine. Secondary audiences include physician assistants and advanced practice nurses. The specialty of family medicine has a prime opportunity through the New Model to transform the discipline. The sense of excitement and the potential surrounding the New Model needs to be communicated effectively to other physicians and health care providers as well, because they will be affected by the changes within family medicine, and they can become important allies in the effort to transform the specialty.

\section{Objective}

The primary objective is for physicians in other specialties to be aware of the strengths of family medicine and to have confidence in the capabilities of family physicians. This awareness and confidence will help ensure a continued strong role for family physicians in serving as patients' primary physician and coordinating care provided by other medical specialists.

\section{Messages to Other Physicians and Health Care Providers \\ - Evidence-based medicine-family medicine has a strong, well-established scientific foundation. \\ - Information management-family medicine uses information management to optimize care. \\ - Continuity-family physicians have continuing responsibility in all aspects of their patients' care. \\ - Inclusiveness - the strengths and benefits of fam- ily medicine are available to all.}




\section{Brand Promises}

By accepting and endorsing all the aspects of the New Model of family medicine, family physicians will be able to achieve the following:

- The best care possible to the patients for whom family physicians share responsibility

- Timely and accurate patient information in a form other physicians and health care providers can understand

- Availability to meet patients' needs

- Availability to meet the needs of other physicians and health care providers

- Rewarding and constructive collegial and community relationships

\section{Strategies and Tactics}

Strategy 1. Family Physicians will be role models throughout the life cycle of other physicians.

\section{Tactics}

- Before medical school-family physicians will be exemplary primary physicians for the patient and the patient's family. Family physicians will enthusiastically seek to provide information on becoming a physician. Family physicians will work to obtain membership and leadership on medical school admissions committees.

- During medical school-family physicians will seek to provide health care to medical students. Faculty, including clinical faculty, will be role models for the professionalism expected by idealistic students. Family medicine residents will have specific instruction as to their role in educating medical students and the training necessary to meet the standard. Rotations in family medicine will be mandatory quality learning experiences.

- During residency-family medicine faculty will be role models for professionalism and be more than willing to be the personal physician to residents and their families. Family medicine residents will learn constructive approaches to shared care relationships.

- During practice-family physicians will strive to be the personal physician to other physicians and their families. Family physicians will meet their brand promises.

- Working with physician leaders-family physicians will be active within the community, serving on public bodies, school and hospital committees, and licensing boards.

Strategy 2. Family medicine's messages will be communicated effectively to specialty societies.

\section{Tactics}

- One-on-one meetings at the national and state level with the leadership of other specialties
- Family physician presentations of best practices at specialty society meetings

- Use of the mass media to project family medicine messages

- Active family physician involvement with the American Medical Association and multispecialty standard-setting entities

Strategy 3. Family medicine's messages will be communicated successfully in all health care settings to individual physicians who are colleagues of family physicians.

\section{Tactics}

- Direct letters and e-mail from referring family physicians

- Mass media

- Trade journals

- Feedback from patients

- State medical societies

Strategy 4. Family medicine's messages will be communicated successfully to physician assistants and advanced practice nurse clinicians.

\section{Tactics}

- Family physicians will serve as the personal physician for students and their families.

- Family physicians will participate as faculty wherever possible.

- Family physicians will seek to maintain the family medicine rotation as the last clinical training for physician assistants.

- Articles will be published in the professional journals of key nonphysician health care provider associations (eg, American Academy of Nurse Practitioners, American College of Nurse Practitioners, American Academy of Physician Assistants).

\section{COMMUNICATION PLAN FOR MEDICAL STUDENTS}

\section{The Audience}

Medical students are key to the advancement of family medicine as a specialty. During the 2002-2003 academic year, 76,905 students matriculated in US medical schools. Of these students, 20,100 were members of the American Academy of Family Physicians. In 1997 nearly 400 family medicine residency programs across the country attracted 2,340 US medical school (MD) seniors through the National Residency Matching Program, representing $17.3 \%$ of US medical school graduates. In the most recent Match, only 1,234 US seniors (fewer than $10 \%$ of US medical school graduates) chose family 


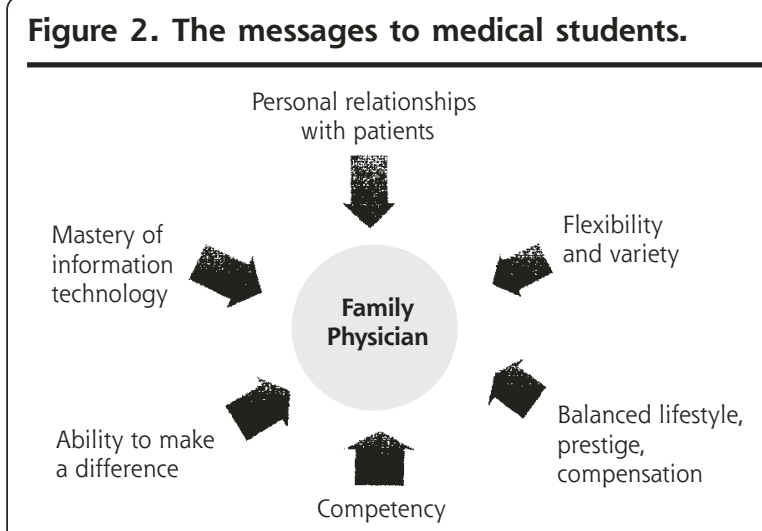

medicine, a decline of nearly $50 \%$ in just 6 years. ${ }^{3}$ This critical audience requires urgent attention.

A modified version of the family physician identity statement developed during the research phase of the FFM project is displayed in Figure 2. This graphic presents the following simple, readily understandable attributes of the specialty, which should resonate with medical students: personal relationships with patients, flexibility and variety, balanced lifestyle, prestige, compensation, competency, opportunity to make a difference, and mastery of information technology.

\section{Objective}

The primary objective is to increase the brand recognition of family medicine among US medical students as a means toward increasing the number of students who select family medicine as a career.

\section{Messages to Medical Students}

- Students who choose family medicine will receive financial and nonfinancial rewards (personal and professional satisfaction).

- Students who choose family medicine will be trained to be competent in professional knowledge and patient relationships, and will be recognized as such upon entering practice.

- Family medicine offers an extremely versatile skill set and a variety of career paths.

- Family medicine offers the opportunity to make a difference in people's lives.

- Family physicians are advocates for their patients and their families as well as for the community as a whole.

- Family physicians use the latest technology to improve patient care.

\section{Brand Promises}

Electing to study and practice the New Model of family medicine provides an opportunity to achieve and experience the following:
- Positive role models

- Quality interactions with patients

- A satisfying career with financial and nonfinancial rewards

- A multidimensional career that provides an opportunity to pursue individual goals

- Intellectual stimulation, it is not a specialty in which physicians will ever be bored

- Technologically advanced health care

- An esteemed career with respect from colleagues and patients

- An opportunity to make a positive difference in the lives of patients, their families, and the community

\section{Strategy and Tactics}

Strategy. Design and implement a comprehensive family medicine career development program, encompassing elementary through postgraduate education, which is coordinated across the discipline and involves all FFM sponsoring organizations. The concept behind this strategy is to engage family physicians across the country in identifying youth who have the potential to become future family physicians.

The program would provide both a structure and specific tools for family physician role models to foster interest in health science careers. The focal point would be the science and art of caring that distinguishes the family medicine model.

Through the program, family physicians would strengthen their presence in local school systems, providing health and related education and guidance targeted to students from elementary through high school. Summer and work experiences in the offices of these physicians would reinforce the health career option as a realistic and compelling one. Their physician mentors would support their college applications.

When these students return home during their college years, they would have an opportunity for credit experiences by performing work or research functions in these same offices. In the process, many would encounter medical students and residents engaged in professional education.

The full-time faculty counterparts of these community physicians (and some community physicians themselves) would simultaneously serve as advocates in the admissions process for these same students, whose applications would be strengthened through their experiences and whose ultimate specialty choice would be positively influenced toward family medicine. These students would, in turn, serve as powerful role models for successive generations of students as they progress through residency, practice, and community and professional leadership. 
Tactics

- Extend preceptor and mentor relationships throughout the educational continuum from elementary school through postgraduate study.

- Develop tiered support systems for successive generations of students.

- Develop a pool of family physicians who have achieved prominence in diverse career roles to serve as a resource to the program.

- Develop alliances with multiple partners in education and other disciplines (eg, the National Education Association and the National Science Foundation).

- Develop a linked scholarship, national placement, and loan forgiveness program to attract family physicians into selected communities, analogous to the National Health Service Corps

- Develop Web-based curricular materials to support health and related education from elementary through high school.

- Develop media guides and Web-based support for family physicians who contribute health messages through mainstream media.

- Develop a "black bag"—a package of diagnostic instruments, office-based laboratory tests, anatomy models, and other audiovisual aids designed to facilitate health education and career promotion by family physicians in local schools.

- Develop a Washington leadership forum, an annual invitational meeting where practicing family physicians and the students they mentor have an opportunity to interact with family physician leaders.

- Develop a leaders' bureau to manage speaking arrangements, internships, and work-study opportunities, and to be the repository of leadership materials from prominent family physicians in diverse career options.

Other tactics that could be used to stimulate student interest in a family medicine career include the following:

- New partnerships with educators, government agencies, and business entities

- Discipline-level commitment to student recruitment, including allocation of appropriate staffing resources to this goal by family medicine organizations

- Public policy intervention that plays to the strength of the specialty in rural and inner-city health

\section{Potential Outcome Measures}

In evaluating the effectiveness of the above initiatives, the following long-term measures could be used:

- Numbers of US medical students electing residency training in family medicine

- Derivative programs initiated with various organizational partners
The following intermediate-term outcomes could be measured:

- Numbers of physicians, students, and others who form relationships

- Log of activities undertaken and their evaluations or success

- Number of students who report a positive influence on career choice

Figures 3 and 4 present possible organizational frameworks for implementation of the comprehensive family medicine career development program.

\section{COMMUNICATION PLAN FOR GOVERNMENT AND OTHER PURCHASERS OF HEALTH CARE}

\section{The Audience}

The audience for this set of messages is entities that provide third party payment for medical services. These organizations includes government health programs (eg, Medicare, Medicaid, the Veterans Administration, and the Indian Health Service), private insurers, and self-insured employers. Because these payers have similar needs and have a shared concern regarding health care costs and expenditures, a similar set of messages and brand promises can be developed.

\section{Messages to Government and Other Purchasers of Health Care}

The New Model of family medicine provides a medical home for the patient. With an electronic medical record and the electronic capability to provide 24-hour access to information, family physicians will be positioned to provide improved access to evidence-based care, with appropriate integration of subspecialty services and elimination of unnecessary services.

A new model of compensation for the services of family physicians will be required if the benefits of the New Model are to be realized. Payers must consider compensation models that provide incentives for information sharing and counseling.

Innovative demonstration models must be undertaken to understand how the concepts of the New Model work in practice.

Continuing with a cost-neutral approach to care can be disastrous. The baby boom generation will require far more resources for care than previous generations. It is unreasonable to expect physicians to adjust their compensation because of inadequate, inequitable reimbursement.

Family physicians are the providers best equipped to integrate health care for beneficiaries of federal programs by serving as their patients' medical home. With appropriate reimbursement that recognizes the importance of preventive and outpatient care, family physicians will 
Figure 3. Organizational relationships of the career development program for family physicians.

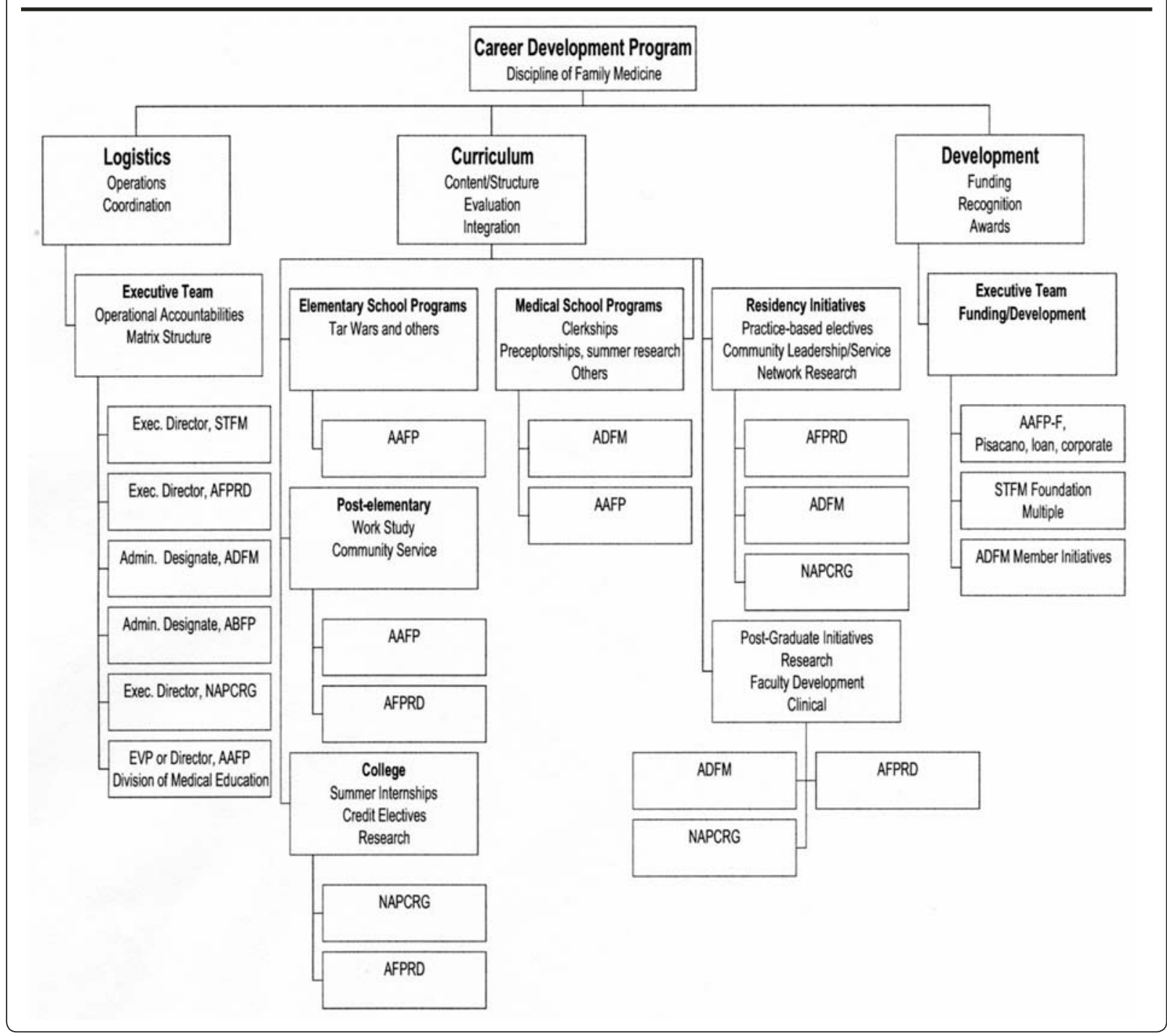

provide more effective care for complex medical conditions, especially in the Medicare population.

\section{Brand Promises}

When the New Model is implemented widely, family physicians promise to provide the following services:

- Appropriate, evidence-based care for the age, gender, and health status of the patient

- Care at an affordable and competitive price

- A seamless medical home of comprehensive primary care services that are available 24 hours per day, 365 days per year

- Care coordination and longitudinal care for patients

\section{Strategies and Tactics}

Strategy 1. Federal Government. Propose a pilot project (or be part of an existing pilot project) that explores new delivery and payment systems for primary care services under Medicare.

\section{Tactics}

- Meet with the Secretary of the Department of Health and Human Services to explain the New Model and the need for pilot sites.

- Create a grassroots campaign targeted toward key US senators and representatives who are involved in Medicare and Medicaid financing issues. Work on legislation for funding pilot demonstrations of the New Model.

- Identify a selective number of practices that could be used as demonstration sites for the New Model. Use these sites to study the impact of the New Model on outcomes and costs.

- Provide the demonstration sites with compensation models that encourage the medical home concept. 


\section{Figure 4. Example of comprehensive family medicine career development program approach to fostering} careers in family medicine.

Alden Family Associates is a busy 3-person practice group in a town of 10,000 with small industry, agriculture and a growing seasonal recreation base. All 3 members of this dynamic group hold clinical faculty appointments at the regional medical school. Each serves as the primary preceptor for 2 medical students during their 1-month, third-year community clerkship

One of the partners, Dr. Amy Winters, provides health services and team support for the local school system on a contract basis and coaches her son's travel soccer team. She also contributes on a voluntary basis to the local Tar Wars program and serves on the Board of the regional Women's Shelter. She updates her Tar Wars presentations through a national Web site supported by the American Academy of Family Physicians, which provides her with ready access to slides, article summaries, and other teaching aids.

Jack, one of her son's 12-year-old friends, begins asking her questions about what it's like to be a family physician. He has a natural gift for relating to people and an interest in science. They arrange a visit to her office, and he decides to join the national youth leadership development program sponsored by the discipline of family medicine.

He eventually works in Dr. Winters' office over 2 summers. His interest in medicine grows, and he applies successfully for a grant from the state chapter of the AAFP to assist with a network research project as a credit course during the middle semester of his sophomore year. While working on this project, he meets one of the 3rd year medical students on rotation from the regional medical school. They strike up a friendship and work together on a presentation to the 6 th grade class at Alden Elementary on violence prevention (a required part of the medical school curriculum). Dr. Winters encourages them to submit their excellent work to the state academy annual scientific meeting. Their presentation is wellreceived, wining third prize and a plaque for Dr. Winters' office.

Jack's application to medical school receives favorable review, in large measure due to his community work, academic record, and a strong recommendation from Dr. Winters. In the summer following college, he participates in the national student leader colloquium in Washington, DC, where he meets with residents and students from around the country, as well as with leading family physicians who are engaged in diverse careers in politics, academics, business, and international relief.

Ultimately, Jack elects a career in family medicine and continues the cycle of mentorship, community activism, and professional achievement. Dr. Winters' son also becomes a physician, to whose practice of general surgery he brings many of the same qualities his mother embodies and with a foundation of mutual respect with his generalist colleagues. He and Jack remain good friends.
- Pursue funding from the Centers for Medicare and Medicaid Services (or another appropriate federal agency) to study how family physicians can best provide care for Medicare patients with complex medical conditions and to identify reimbursement methods that support such an approach to care.

- Develop a public relations campaign to educate patients and their families about the importance of a reimbursement system that rewards quality, prevention, and integrated health care services.

Strategy 2. Insurers and Employers. Schedule meetings with executive management of private payers and large self-insured employers to explain the New Model and how it will enhance the goal of providing more cost-effective care while improving quality. Develop and implement demonstration projects to present to high-profile employers and third party payers.

\section{Tactics}

- Schedule one-on-one meetings with large national insurers and the professional associations that represent their interests (eg, the American Association of Health Plans and the national Blue Cross and Blue Shield Association), large self-insured employers, business groups (eg, the US Chamber of Commerce and the Washington Business Group on Health), and large labor unions (eg, the Service Employees International Union).

- Use these meetings as a way to (1) explain conceptually the major features of the New Model, (2) show how the New Model works in practice by sharing examples from family medicine practices that have incorporated features of the New Model, (3) present a new payment system to support the New Model, and (4) propose pilot projects to show how the New Model can provide superior care in a more cost-effective manner than the traditional model. 


\section{COMMUNICATION PLAN FOR THE PUBLIC (PATIENTS)}

\section{The Audience}

The primary audience to whom this communication plan would be directed is patients who receive care directly, as well as those who are responsible for making decisions regarding another's care (eg, for a child or an aged parent).

\section{Messages to the Public}

The primary message for this audience, which is based largely on FFM research on the public's desires and expectations, should emphasize the following characteristics of family physicians:

- Relationship-centered care-family physicians provide patients with a personal connection with a primary care physician whom they know and trust.

- Knowledgeable_family physicians have a broad range of knowledge and expertise. The specialty is solidly grounded in scientific knowledge.

- Competent-family physicians are able to manage the most common health related issues, but are skilled at making appropriate referrals to other specialists when appropriate.

- Responsive to patients' needs-family physicians listen to patients and take the time to identify the most appropriate solution to their needs, when they need it.

- Focused on a holistic approach - the orientation of family medicine is on integrated, whole person care, from wellness and prevention to acute care.

\section{Brand Promises}

Family physicians will serve patients' primary medical needs by promising to do the following:

- Stay current on burgeoning medical information

- Use technology, as appropriate, to enhance health

- Listen to the patient and seek positive solutions to meet individual patients' needs

- Be available when care is needed

- Incorporate a whole-person orientation in managing care

- Serve as an effective advocate to ensure that health care needs are met

- Work with the patient to establish a personal relationship, designed to have a positive influence on outcomes

- Honor the trust and confidence that the patient places in the family physician

\section{Strategies and Tactics}

Strategy. Develop and utilize messages and branding and marketing tools to communicate to the public the characteristics and value of family medicine and the role of family physicians in providing primary care.
Tactics

- Develop a press strategy to communicate core messages

- Create an advertising campaign that highlights the renewed role of family medicine.

- Identify media-friendly spokespersons who can establish an ongoing presence in the media.

- Place a family physician on a popular television series, even in a guest role.

- Create a radio show (eg, on National Public Radio) around family medicine.

- Promote the concept of a regular monthly family medicine column to parenting and family magazines.

\section{Physical Traits of the Brand}

Finally, in all of the communications plans that are implemented, the following steps should be taken to ensure brand consistency:

- Adopt a single name to identify the disciplineconsistently refer to the discipline as family medicine. Eliminate the descriptor family practice in all communications

- Conduct a brand audit - conduct a brand audit of the public materials of supporting organizations to ascertain consistency and relevancy of messages.

- Create a co-branded enduring logo_change family medicine's iconic logo to an icon that can easily be co-branded to individual practices and is graphic rather than figurative. In this way, it will not become outdated and can be entirely culturally inclusive, since it is not figuratively rendered.

- Create branding materials and templatesdevelop personalized supporting organization branding elements that can be offered at reasonable prices to interested members and provide templates that can be customized for their use.

By taking these steps and actively implementing the communications plans described above for family medicine's target audiences-family physicians, other physicians and health care providers, medical students and residents, public and private payers, employers, and patients - the specialty can enhance the impact of the New Model and help ensure that it becomes implemented on a widescale basis.

\section{SUMMARY AND CONCLUSIONS}

The specific content of this report is a snapshot, a reading of best evidence at the time of its writing. Some of the elements in our portrait will endure and require a longitudinal commitment from the discipline. Others will fade or need refreshment as the dynamic health care marketplace evolves. Some that currently stand in the background will press forward or come into clearer 
focus, demanding our eye. Additional target audiences will likely surface. Academic health centers, a continuing strategic challenge for the discipline of family medicine, are an example.

Perhaps this exercise serves as much to illustrate a method as to convey content. Whatever directions lie ahead, none will be successful without a vigorous and disciplined communications plan, keyed to a consistent brand focus and with targeted messages and strategies to address diverse constituencies.

\section{RECOMMENDATIONS}

Recommendation 1.1. That the organizations involved in family medicine make a multiyear commitment of resources to implement and support the communications plans described in this report, which are based on key messages to target audiences.

Recommendation 1.2. Replace the name family practice with family medicine. For clarity and consistency, the entire family of family medicine should implement this change.

Recommendation 1.3. Create a new graphic symbol for family physicians that will be recognized by those inside and outside family medicine.

Recommendation 1.4. Sustain a disciplined program of self-analysis to measure the effectiveness of the communications plans implemented in support of the New Model, preferably using existing baseline data.

To read or post commentaries in response to this article, see it online at http://www.annfammed.org/cgi/content/full/2/suppl_1/S75.

Key words: Communication; professional role; social identification

Funding Support: The Future of Family Medicine Project is supported by the following family medicine organizations: American Academy of Family Physicians (AAFP), American Academy of Family Physicians Foundation (AAFPF), American Board of Family Practice (ABFP), Association of Departments of Family Medicine (ADFM), Association of Family Practice Residency Directors (AFPRD), North American Primary Care Research Group (NAPCRG), and Society of Teachers of Family Medicine (STFM). Major support has been contributed by Eli Lilly Foundation; Pharmacia, Pharmacia Foundation; Pfizer, Pfizer Foundation; and the Robert Wood Johnson Foundation. In addition, generous support has been obtained from the Health Resources and Services Administration, Schering-Plough Corporation, and Wyeth Pharmaceuticals.

Members of Task Force 4: John C. Dickinson, MD, Chair, Rochester, NY; Kenneth L. Evans, MD, Vice Chair, Stillwater, Okla; Thomas R. Berry, PA-C, MBA, Glen Gardner, NJ; Carla Cesario, Wakefield, Rl; Joel Feigin, MD, Kenilworth, NJ; Carole Feld, Washington, DC; Tristan Guevara, DO; Grosse Pointe Farms, Mich; Beulette Y. Hooks, MD, Buena Vista, Ga; Mike Magee, MD, New York, NY; Lee Newcomer, MD, Minneapolis, Minn; Michael J. Scotti, Jr, MD, Chicago, Ill; Joseph E. Scherger, MD, MPH, Del Mar, Calif; Jan Carter, MBA, Staff Executive, Leawood, Kan; Cynthia Stapp، Assistant Staff Executive, Leawood, Kan.

Acknowledgments: The task force benefited greatly from the input of many people, including all the members of the Future of Family Medicine
Project Leadership Committee, the Family Medicine Working Party, FFM project and task force staff, members of the other FFM task forces, and particularly the group of external reviewers listed below.

Project Leadership Committee: James C. Martin, MD, Project Leadership Committee Chair; Robert F. Avant, MD; Marjorie A. Bowman, MD, MPA; John R. Bucholtz, DO; John C. Dickinson, MD; Kenneth L. Evans, MD; Larry A. Green, MD; Douglas E. Henley, MD; Warren A. Jones, MD; Samuel C. Matheny, MD, MPH; Janice E. Nevin, MD, MPH; Sandra L. Panther, CFRE; James C. Puffer, MD; Richard G. Roberts, MD, JD; Denise V. Rodgers, MD; Roger A. Sherwood, CAE; Kurt C. Stange, MD, PhD; Cynthia W. Weber, MA.

Future of Family Medicine Research Advisory Committee: John R. Bucholtz, DO; John C. Dickinson, MD; Larry A. Green, MD; Warren A. Jones, MD; James C. Martin, MD; Richard G. Roberts, MD, JD; Kurt C. Stange, MD, PhD.

Future of Family Medicine Project Staff: Norman B. Kahn, Jr, MD, FFM Staff Executive; Sarah Thomas, Assistant Staff Executive; Marilyn A. McMillen, MBA, Project Manager; Dorothy Young, FFM Administrative Assistant; Nina Carnoali, FFM Staff Assistant; Ruth Coram, FFM Staff Assistant.

\section{References}

1. Magee M. Major Environmental Forces Shaping Health Care and the Future of Family Medicine. Prepared especially for this project. Copy on file in the Division of Strategic Planning and Marketing, American Academy of Family Physicians.

2. Burns LB, McCormick JB, Borroni-Bird CE. Vehicle of change. Sci Am. 2002;287:64-73.

3. American Academy of Family Physicians. Division of Medical Education. 2003 match results and information. 2003 MATCH information sheet. Available at: http://www.aafp.org/match.

\section{Other Sources}

Baker L, Wagner TH, Singer S, Bundorf MK. Use of the Internet and e-mail for health care information: results from a national study. JAMA. 2003;289:2400-2406.

Collins J. Good to Great. New York, NY: HarperCollins Publishers, Inc.; 2001.

Dworkin B. How Ontario drove doctors away. The Ottawa Citizen. March 5, 2003:A12.

Feinberg DM. Will neurology residents with large student loan debts become academicians?[comment]. Neurology. 2002;59:789.

Gelfand DV, Podnos YD, Wilson SE, Cooke J, Williams RA. Choosing general surgery: insights into career choices of current medical students. Arch Surg. 2002;137:941-945.

Gill D, Palmer C, Mulder R, Wilkinson T. Medical student career intentions at the Christchurch School of Medicine. The New Zealand Wellbeing, Intentions, Debt and Experiences (WIDE) survey of medical students pilot study. Results part II. N Z Med J. 2001;114:465-467.

Grayson MS, Klein M, Franke KB. Impact of a first-year primary care experience on residency choice. J Gen Intern Med. 2001;16:860-863.

Lofsky S. Family medicine in decline?[comment]. CMAJ. 2002;167:845.

Magee M. Relationship-based health care in the United States, United Kingdom, Canada, Germany, South Africa, and Japan. Paper presented at: The World Medical Association "Patient Safety in Care and Research"; September 11, 2003; Helsinki, Finland.

Medalie JH, Zyzanski SJ, Langa D, Stange KC. The family in family practice: is it a reality?[comment]. J Fam Pract. 1998;46:390-396.

Owen JA, Hayden GF, Connors AF, Jr. Can medical school admission committee members predict which applicants will choose primary care careers? Acad Med. 2002;77:344-349. 
Rabinowitz HK. Recruitment, retention, and follow-up of graduates of a program to increase the number of family physicians in rural and underserved areas. [comment]. New Engl J Med. 1993;328:934-939.

Rabinowitz HK. The relationship between medical student career choice and a required third-year family practice clerkship. Fam Med. 1988;20: 118-121.

Rabinowitz HK. The role of the medical school admission process in the production of generalist physicians. Acad Med. 1999;74(1:Suppl):Suppl-44.

Rabinowitz HK, Diamond JJ, Markham FW, Paynter NP. Critical factors for designing programs to increase the supply and retention of rural primary care physicians. JAMA. 2001;286:1041-1048.

Rosenthal MP, Diamond JJ, Rabinowitz HK, et al. Influence of income, hours worked, and loan repayment on medical students' decision to pursue a primary care career.[comment]. JAMA. 1994;271:914-917.
Rosenthal MP, Turner TN, Diamond J, Rabinowitz HK. Income expectations of first-year students at Jefferson Medical College as a predictor of family practice specialty choice. Acad Med. 1992;67:328-331.

Rosser WW. The decline of family medicine as a career choice.[comment]. CMAJ. 2002;166:1419-1420.

Rothman AA, Wagner EH. Chronic illness management: what is the role of primary care? Ann Intern Med. 2003;138:256-261.

Senf J, Campos-Occult D, Kotub R. What Do We Know About Factors Related to the Choice of Family Medicine as a Specialty? (Arizona Study) Web site. Available at http://www.aafp.org/x19661.xml.

Spar IL, Pryor KC, Simon W. Effect of debt level on the residency preferences of graduating medical students. Acad Med. 1993;68:570-572.

\section{Appendix A. Research in Support of FFM Task Force 4 Report}

Relevant research is from the Family Practice Working Party and Academic Family Medicine Organizations, which is available at the Future of Family Medicine (FFM) Web site at: http://www.futurefamilymed.org. Communication Plan for Family Physicians.

Reimbursement-Most family physicians are concerned about inadequate reimbursement for their services. Family physicians wish to have better reimbursement. Financial and income concerns dissuade many medical students from pursuing careers in family medicine.

Confusion with name- $75 \%$ of family physicians are satisfied with the name "family practice" but believe it is not sufficiently scientific.

Comprehensiveness of the discipline-Patients do not feel comfortable with the ability of any one physician to handle a broad range of medical problems.

Confusion to patients - The general patient population does not know all the things family physicians can do. Family medicine is not well understood: $38 \%$ of those surveyed did not realize family physicians are primary care physicians. Most family physicians are satisfied with the deep relationships they establish with their patients over the years. The variety that family medicine presents and the whole-person orientation leads to job satisfaction among family physicians.

Scientific-Patients want their physicians to have state-of-the-art equipment.

Collegiality_-Specialists refer more patients to general internists than family physicians; they think general internists are better diagnosticians than family physicians (56\% and $4 \%$, respectively); and they believe family physicians would benefit from more training.

Public perception-Most medically sophisticated patients believe family physicians are held in less regard than their colleagues; $85 \%$ of patients do not know one primary care physician from another.

\section{Communication Plan for Other Physicians and} Health Care Providers

FFM research found that physicians in specialties other than family medicine:

- Differ on referring patients to family physicians or general internists

- Receive referrals from both without distinction

- Believe training, skills, and capabilities are more similar than distinctive

- Believe family physicians offer a wider range of services

- Believe general internists are more knowledgeable

- Believe the general public holds family physicians in lower regard

- Believe the contributions of family physicians are valuable

- Believe family physicians are more relevant in a managed care environment

- Believe family physicians are better suited as a first contact for patients

- Believe family physicians do very well in many attributes and services, with the exception of managing serious illness, including continuity, comprehensiveness, relationships, and the practice of preventive medicine

- Believe general internists are more up-to-date and better diagnosticians and have better in-depth training than family physicians, and would recommend more training for family physicians

The qualitative research findings also addressed other specialists' beliefs concerning family physicians:

- Family medicine is important, vital to the health care system.

- Family physicians are altruistic, idealistic, better able to deliver preventive medicine.

- Family physicians are better for younger families, rural communities, and people who want warmth, compassion, and empathy. 
- Family physicians need to articulate their distinctness and avoid a gatekeeper reputation.

The House of Delegates of the American Medical Association has several policies reflecting on family medicine and primary care that are reflective of the general attitude of physicians:

- More primary care physicians are greatly needed.

- Family medicine residencies should receive federal and state support.

- Primary care physicians should be better paid.

- Clinical departments of family physicians should be established on equal grounds with other specialties.

- Residency training should be encouraged at community hospitals.

- Principal care should be provided or coordinated by a family physician.

\section{Communications Plan for Medical Students} Financial and other rewards-FFM research found the literature confirms the impact of financial and other expected rewards (not just financial) on specialty choice: $84 \%$ of students choose the specialty on the basis of emotional rewards; $93 \%$ choose the specialty on the basis of making a difference in people's lives; no one believes that family physicians are highly paid.

Knowledge- $-92 \%$ of students report intellectual stimulation to be a strong motivator in specialty choice; personal physician (family physician) is most trusted source of information, enabling knowledge mastery by access to evidence at the point of care is appealing.

Relationships-Survey data confirm that the patient-physician relationship is a leading factor of importance to patients, students, and physicians $91 \%$ of students report that the opportunity to have satisfying relationships with patients is an attractive feature of family medicine.

Versatility and variety- $95 \%$ of those choosing the specialty were attracted to its variety; $92 \%$ regard the specialty as having high intellectual stimulation.

Advocacy-93\% of students choose the specialty, at least in part, because it provides a chance to make a difference in people's lives. FFM research findings highlight family medicine's community focus as a core attribute of the specialty.

\section{Communication Plan for Patients}

FFM research included some of the following conclusions of the independent researchers regarding FFM data:

- "Society, generally, is enamored with science and technology, which, in turn, influences perceptions of what is regarded as medically 'critical.' Family practice, however, is associated with neither."

- "Patients frequently want the newest high-tech gizmo or pill they've seen on TV. They understand that their family physician isn't going to be the one to give them that."

- Misunderstanding of family medicine: The public doesn't understand what family medicine represents. There is a lack of awareness that family physicians are primary care physician specialists; only 1 in 10 Americans name them as so. There is a lack of awareness among the public that they are going to a family physician, many who think they are, aren't.

- Choosing a family physician-The primary mode for choosing a family physician is word of mouth. Patients learn of the specialty through a variety of sources, often after selecting a physician, by seeing the diploma or business card in the office, through an insurance list or guidebook, from the physician himself or herself, by the person who referred the patient to the physician, or from a friend or relative.

- The public believes family physicians excel in the following ways:

1. Being honest and direct

2. Having a good reputation

3. Taking the time to explain everything

4. Not hesitating to refer patients to specialists

5. Having good listening skills

6. Encouraging steps for a healthier life

7. Being understanding, supportive, and nonjudgmental

8. Acting as a partner in maintaining health

9. Treating serious and nonserious conditions

10. Attending to both emotional and physical health

11. Encouraging a healthier lifestyle

12. Trying to get to know each patient

13. Being able to help with any problem

14. Being someone patients can stay with as they grow older

- Consumers' attitudes about family physicians mirror how family physicians view their role, attributes, and what they like about the job.

- Ranking by physicians-greatest satisfaction in job:

1. Making a difference

2. Bonding with patient

3. Seeing patients get better

4. Continuity of care from cradle to grave

5. Appreciation shown by patients

6. Becoming part of patients' lives 